\title{
Neimark-Sacker, flip and transcritical bifurcation in a symmetric system of difference equations with exponential terms
}

\author{
Chrysoula Mylona ${ }^{1}$, Garyfalos Papaschinopoulos ${ }^{1}$, and Christos Schinas $^{2}$ \\ ${ }^{1}$ Democritus University of Thrace \\ ${ }^{2}$ Democritus Univ. of Thrace
}

February 15, 2021

\begin{abstract}
In this paper, we study the conditions under which the following symmetric system of difference equations with exponential terms: $\backslash\left[\mathrm{x}_{-}\{\mathrm{n}+1\}=\mathrm{a}_{-} 1 \backslash\right.$ frac $\left\{\mathrm{y}_{-} \mathrm{n}\right\}\left\{\mathrm{b}_{-} 1+\mathrm{y}_{-} \mathrm{n}\right\}+\mathrm{c}_{-} 1 \backslash$ frac $\left.\left\{\mathrm{x} \_n e^{\wedge}\left\{\mathrm{k}_{-} 1-\mathrm{d}_{-} 1 \mathrm{x}_{-} \mathrm{n}\right\}\right\}\left\{1+\mathrm{e}^{\wedge}\left\{\mathrm{k}_{-} 1 \mathrm{~d}_{-} \_1 \mathrm{x}_{-} \mathrm{n}\right\}\right\}, \backslash\right] \backslash\left[\mathrm{y}_{-}\{\mathrm{n}+1\}=\mathrm{a}_{-} 2 \backslash \mathrm{frac}\left\{\mathrm{x}_{-}-\right.\right.$

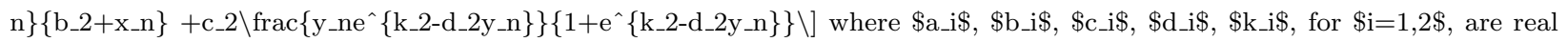
constants and the initial values $\$ \mathrm{x}_{-} 0 \$, \$ \mathrm{y}_{-} 0 \$$ are real numbers, undergoes Neimark-Sacker, flip and transcritical bifurcation. The analysis is conducted applying center manifold theory and the normal form bifurcation analysis.
\end{abstract}

\section{Hosted file}

Mylona.pdf available at https://authorea.com/users/368914/articles/508924-neimark-sackerflip-and-transcritical-bifurcation-in-a-symmetric-system-of-difference-equations-withexponential-terms

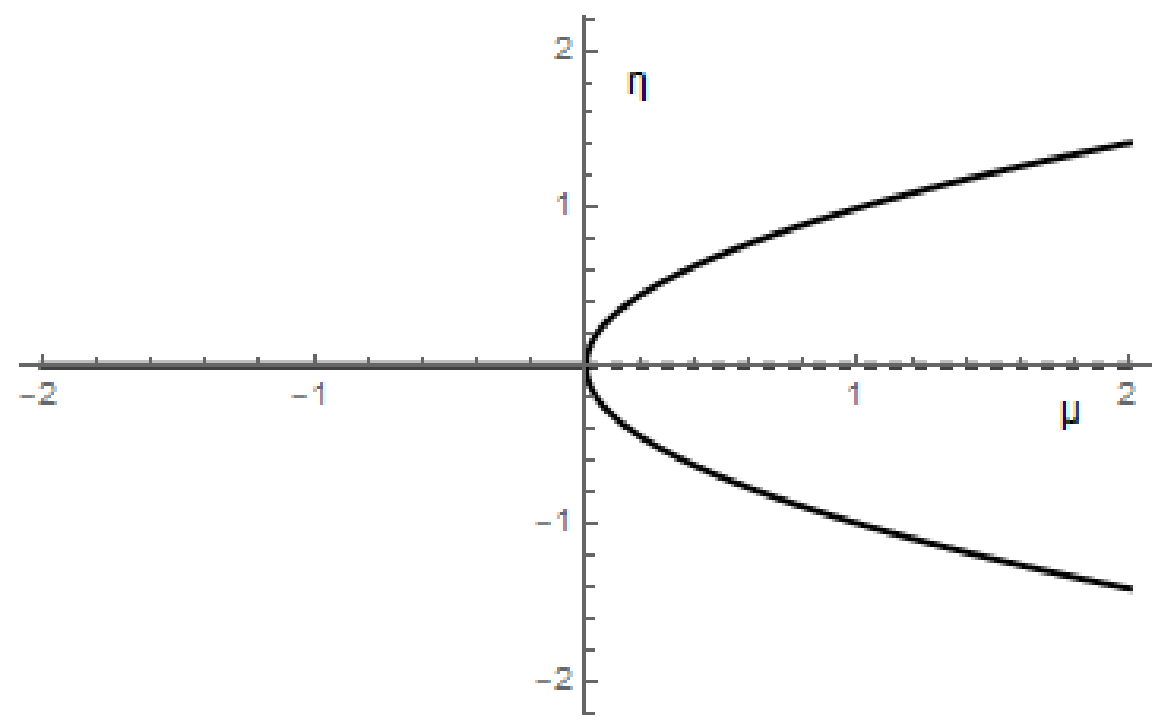




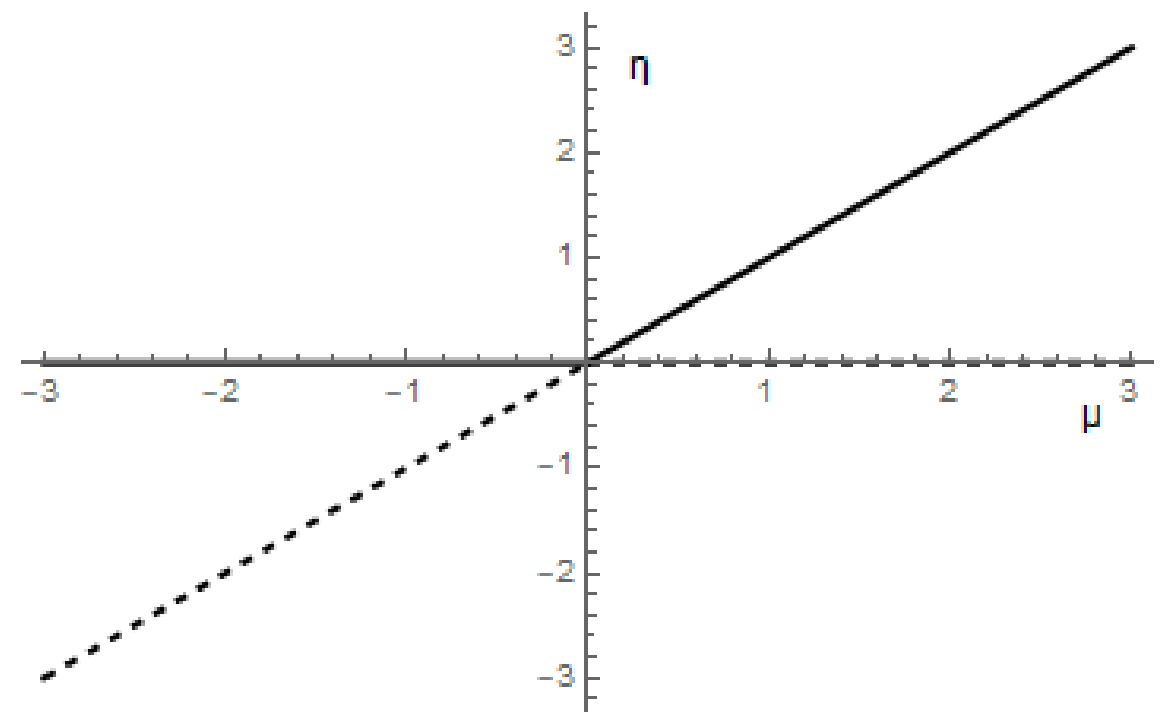

